\title{
8
}

\section{Support for Those Living with Dementia and Their Caregivers}

In 2015, an estimated 46.8 million people in the world were living with dementia. ${ }^{1}$ That number is expected to nearly double every 20 years, and by 2050 is projected to reach 131.5 million. $^{2}$ Forty-nine percent of the new dementia cases are seen in Asia, 25 percent in Europe, 18 percent in the Americas, and 8 percent in Africa. ${ }^{3}$ In 2015 the global costs of dementia were estimated to be US $\$ 818$ billion, which represents a 35.4 percent increase since $2010 .{ }^{4}$ In the US, the annual cost of dementia care is estimated at US\$159 to US $\$ 215$ billion $^{5}$ and is projected to grow to US $\$ 1.1$ trillion by $2050 .{ }^{6}$ Most dementia care costs can be attributed to long-term care and not medical care. Institutional and informal home care is responsible for 75 to 84 percent of the total costs of dementia. ${ }^{7}$

\section{Caregiving}

Dementia is one of the leading causes of disability and dependency for older adults worldwide. ${ }^{8,9}$ Approximately one half of those in need of caregiving have dementia. ${ }^{10}$ In the next decade, the US will need 1.3 million more paid caregivers. ${ }^{11}$ The approaching need, combined with 
the caregiver shortage that already exists, will present care challenges that could place an even larger burden on the shoulders of informal caregivers.

Informal caregivers are family or relatives, mostly female, ${ }^{12}$ who provide unpaid care and support. Informal caregivers face financial, emotional, and physical strain. They are more likely to experience physical health problems, depression, and anxiety. ${ }^{13}$ Some are forced to leave the workforce. Sixty-eight percent of family caregivers in the US reported that they had to make work accommodations including retiring, working part-time, or taking time off. ${ }^{14}$

Informal caregivers provide the bulk of dementia care. ${ }^{15}$ Thirty-four percent of the informal caregivers in the US are 64 or older. ${ }^{16}$ Dementia care exceeds the demands of many other chronic conditions. Those with dementia require more assistance with activities of daily living ${ }^{17}$ and can exhibit emotional behaviors that are unfamiliar and difficult to manage. Most informal caregivers are not prepared, nor do they have the training for the tasks needed to provide the necessary care. ${ }^{18,19}$

In 2010, of the adults age 70 and older who received informal care, an estimated 3.6 million had cognitive impairment that was likely dementia. ${ }^{20}$ In 2016 informal caregivers in the US provided 18.2 billion hours valued at over US $\$ 230$ billion. $^{21}$ More than 40 percent of the costs of dementia care globally can be attributed to informal caregivers. ${ }^{22}$ This is a valuable cost savings to public and private healthcare insurers. With this knowledge, insurers and managed healthcare systems have a vested interest in supporting informal caregivers. Support for informal caregivers has shown to improve well-being for the caregiver and the person living with dementia. ${ }^{23}$ Caregiver support has also shown to delay institutional care. ${ }^{24}$

There is no drug yet available that can prevent or cure dementia, but psychosocial interventions have been proved to have a significant positive impact on persons with dementia and their caregivers. (Dr. Mary S. Mittelman)

\section{Dr. Mary S. Mittelman, NYU Caregiver Intervention}

Mary Mittelman is the director of the Psychosocial Research and Support Program at the Center for Cognitive Neurology at New York University. 
She is also a research professor at the Department of Psychiatry and the Department of Rehabilitation Medicine at NYU School of Medicine.

Along with an expert team, Mary developed the NYU Caregiver Intervention in her lab at the NYU School of Medicine. The evidencebased intervention provides psychological support to the informal caregiver for someone living with dementia. The intervention includes two individual counseling sessions, four family counseling sessions, weekly support groups, and "ad hoc" counseling available by phone to the family and caregiver. Counselors offer support to the caregiver and the family throughout the course of the caregiving journey and up to two years after.

Everyone is interested in research on drug trials and how drugs can improve cognitive function. I think that we should be equally concerned with wellbeing and quality-of-life for those with dementia, their caregiver, and their family.

The initial research of the intervention began with a randomized control trial in 1987. The caregivers in the treatment group experienced positive outcomes including fewer symptoms of depression, increased satisfaction with support from family, less reactivity to the person who they were caring for, and improved physical health. Another notable outcome was that the caregivers in the treatment group were able to keep their family member at home for, on average, one and half years longer than those in the control group.

The intervention has been well documented in peer-reviewed journals. ${ }^{25,26,27,28}$ Since the initial research, there have been many well-documented translations of the intervention in the US. ${ }^{29,30,31,32,33}$ Other translations were conducted in the United Kingdom, Israel, and Australia. In 2015, New York State Governor Andrew M. Cuomo granted NYU Langone Medical Center US\$7.5 million to launch the Family Support Program, making the NYU Caregiver Intervention available to residents throughout New York City who are caring for someone with dementia. Mary and her team are planning to serve 600 caregivers annually in this program.

In her interview, Mary compared the intervention to a cake. Leaving out an important ingredient or changing the timing or dosage will not result in the cake you had planned. Mary explained that the most 
important component of the intervention is family involvement. The ability of the caregivers in the treatment group to keep their family member home for a year and a half longer than those in the control group was due to their social support, emotional support from family and friends, assistance from family and friends, and the number of people the caregiver felt close to. Those who have tried to replicate the intervention without the family piece have not realized the successful outcomes.

An unsuccessful replication led Mary and her team to write a book entitled Counseling the Alzheimer's Caregiver: A Resource for Healthcare Professionals. ${ }^{34}$ Mary and her team also decided to develop an online training course to ensure the validity of future replications. The training incorporates videos of case studies along with text and video commentary. Today, anyone in the world looking to offer the NYU Caregiver Intervention has the tools to do so.

Mary and her team were concerned that family members who wish to participate might have issues with traffic and transportation, varying hours of availability, or could live in other state or even country. Those concerns led to the creation of a videoconferencing version of the intervention.

It is time that insurers understand the importance of treating the caregiver.

When a caregiver feels lower levels of stress and depression, they make less use of the healthcare system for their own needs. This represents a cost savings to the insurer. The other substantial cost savings results from the ability of the caregiver to keep the family member home for a year and a half longer. Mary is convinced that the intervention should be reimbursed by insurance. Recently there was a letter circulating in the Senate that explained the importance of caregiver support. That letter mentions the New York University Caregiver Intervention. It is our hope that the increasing awareness of the value of supporting the caregiver of someone with dementia will influence insurers and managed care providers in the US and healthcare systems worldwide. 
This is our time to care.

Every mother. Every father. Every child. Every New Yorker.

It takes a certain kind to rise to this challenge.

The courageous kind. The resilient kind. The loving kind. Our kind.

We are CaringKind. The Heart of Alzheimer's Caregiving.

Fig. 8.1 CaringKind entrance welcome

Those living with dementia, their caregivers, and their families benefit from services, education, and supports. Professionals of all disciplines who work with people living with dementia need dementia-specific training to better serve their clientele (See Fig. 8.1).

\section{Jed A. Levine, CaringKind}

Jed Levine is the Executive Vice President and Director of Programs and Services at CaringKind in New York City.

For more than 30 years, CaringKind has been providing free education, support, assistance, and training for those living with early stage dementia and their caregivers. Approximately 15,000 people, including, 
trainees, volunteers, support group members and those seeking other services, walk through the CaringKind doors each year. CaringKind also trains and educates professionals who serve those living with dementia. They offer approximately 90 support groups that are held throughout New York City in community centers, hospitals, churches, synagogues, nursing homes, and community-based organizations. CaringKind also operates a 24-hour telephone hotline that receives approximately 750 to 900 calls each month. The employees manning the call line provide comfort and connect callers to additional supportive services.

We recognize that the person receiving the diagnosis and their family are in a lot of emotional pain. Sometimes they are paralyzed with fear and the feeling of helplessness. Most people do not know where to begin. If they call us for information and direction, they also receive validation for what they are experiencing. We assure them that they do not have to face the challenge alone. (Jed A. Levine)

\section{Mission}

In his interview, Jed explained that the funding for CaringKind is approximately 85 percent philanthropic and 15 percent governmental and other sources. Many of the CaringKind board members view their service as a personal mission because the disease has touched their family or friends. A personal connection to dementia can unite a group or organization through a shared mission. With the growing rates of dementia, it is likely everyone will eventually share this personal connection.

\section{Minorities and Dementia}

Jed mentioned that CaringKind was making strides in their efforts to reach minority communities. When Jed joined CaringKind, he was dedicated to making sure that anyone in need of CaringKind's services would be supported by someone who speaks their language and understands their culture. Chinese immigrants represent the second largest group of foreign 
citizens in New York and they are projected to eventually take first place over Dominican born residents. ${ }^{35}$ CaringKind has a full-time outreach manager in the Chinese community to raise the visibility of the disease and encourage people to engage with the supports available to them. CaringKind has made such strides within the Asian community that they have hired a full-time social worker to support the Chinese families seeking assistance. They have also hired a trainer who speaks Cantonese and Mandarin to teach workshops and training to families and caregivers. CaringKind has made the same inroads with the Latino Community.

African Americans are more likely to develop Alzheimer's than Whites with estimates ranging widely from 14 to 100 percent. $^{36}$ They are also twice as likely to develop late-onset Alzheimer's and are less likely to seek a diagnosis of their conditions. ${ }^{37}$ Jed noted that it took CaringKind longer to establish trust within the African American community than any other communities they serve. It took the outreach manager five years to convince the African American communities to trust that CaringKind would be there to support them. Now African Americans attend dementia-specific legal and financial workshops and use the social work and supportive services at CaringKind.

\section{The Early Stage Center}

The Early Stage Center fills the gap between those who cannot function independently in programs designed for people without dementia and those who have not yet progressed to the stage of needing adult day programs. It also fills the need for social interaction in a safe and accepting environment. Support groups enable participants to share their fears and grief. Jed mentioned that participants create empowering connections through their shared experiences. They laugh and they cry but leave feeling supported. Many participants have not yet told their family or friends that they have been diagnosed. Jed noted that it is a powerful experience to hear people tell their story publicly for the first time.

The Early Stage Center connects their members to art museums, historical museums, botanical gardens, and musical performances. The events are socially and culturally enriching experiences. Jed mentioned 
that music and art have a special connection into the brain of those living with dementia. The Early Center also has a variety of programs including meditation, yoga, art, film, theater, and photography. The photography program is popular because the photos are often stunning and are taken by both experienced and novice photographers. Geri Taylor, a participant of the photography program, allowed a New York Times reporter to document her journey with Alzheimer's for two years. ${ }^{38}$ Providing supports and services for someone living with dementia is important, but it is also essential to train the healthcare workforce serving those living with dementia.

\section{Workforce Training}

One cannot underestimate the importance of training the healthcare workforce in dementia care and communication. The US is already lacking in a workforce trained in dementia, and the shortage of physicians, nurses, and social workers is expected to continue to rise. ${ }^{39}$ CaringKind offers dementia training to professionals, including homecare workers, certified nursing assistance, and people working in long-term care. They also provide education to nursing and social work schools. CaringKind has an education program for chaplains who wish to learn more about dementia so they can better serve the spiritual needs of their congregants with dementia.

\section{Financial and Legal Planning}

Jed described that, in the US, legal and financial planning is important for those with dementia and their families. It is not uncommon for one spouse to spend down their savings and even lose their home to pay for long-term care for their spouse with dementia. This leaves the surviving spouse financially insecure. It is estimated that 20 percent of those caring for someone with dementia go hungry because they cannot afford enough food. ${ }^{40}$ In other cases, the spouse who handles the finances is the one with dementia, making them vulnerable to scams and risky 
financial decisions. CaringKind connects their clients with experts in these areas for financial counseling. CaringKind also connects families to attorneys for guidance in durable power of attorney and estate planning.

\section{Respite}

Respite provides caregivers a temporary break while someone else assumes the care responsibilities. Respite varies in duration from an hour to run errands to several days to take a vacation. Respite can result in lower levels of caregiver burnout and better care for the person living with dementia. CaringKind offers respite services to their members. Social workers also help members to design a long-term care plan with scheduled respite periods.

\section{Palliative Care Pilot Program}

CaringKind is dedicated to raising the awareness of palliative care for those living with dementia. They conducted three pilot programs of the Beatitudes Campus Comfort Matters ${ }^{\mathrm{TM}}$ palliative care model $^{41}$ in three nursing homes in New York including the Isabella Geriatric Center, The New Jewish Home, and Cobble Hill Health Center. The pilot involved a two-year training and integration plan with the goal of certifying the three providers in Comfort Matters ${ }^{\mathrm{TM}}$. Jed is convinced that this model can transform the lives of those living in residential care.

\section{Wandering}

Sixty percent of those with dementia will wander, and all people with memory challenges are at risk for wandering. ${ }^{42}$ Some claim that dementia wandering is driven by desire for those living with dementia to return to their younger days. ${ }^{43}$ If they were ranchers, they might wish to go outside each morning to check on the cows and if they were homemakers, they might wish to leave to drive their children to and from school and activities. In Chap. 2 we examined person-centered methods to alleviate 
the desire of residents in long-term care to wander. Prevention may be more difficult with untrained caregivers in the home. When the person living with dementia wanders and becomes disoriented or confused, he or she will not be able to find their way home. This elopement can present many dangers for the person with dementia and much stress for their families and caregivers. CaringKind has a low-tech, high-impact program for finding people with dementia after they have wandered.

\section{Elizabeth Bravo Santiago, CaringKind}

Elizabeth Bravo Santiago is the Director of the MedicAlert ${ }^{\oplus}$ NYC Wanderer's Safety Program at CaringKind. ${ }^{44}$

The MedicAlert ${ }^{\circ}$ NYC Wanderer's Safety Program is a collaboration between the New York City Police Department, the New York City Office of Emergency Management, the New York City Department for the aging, the Port Authority, the Transit Authority, the New York City Police Department Housing Bureau, other responders, and CaringKind. The mission of the program is to locate people with dementia who have gone missing. Approximately 21 searches arise through the MedicAlert ${ }^{\circ}$ NYC Wanderer's Safety Program monthly. Elizabeth also coordinates with the police department's Silver Alert system, which is an alert for missing people who are 65 or older. Elizabeth assists in finding an average of 40 people each month through the two programs. In her 13 years directing the program, all but two people were found alive.

\section{How the Program Works}

When a person has wandered, a family member or caregiver calls 911 . The police department takes a report and sends it to the Missing Persons detective unit. The detective then visits the home of the missing person to learn more information from their family and or caregiver. The detective canvasses the appropriate area and alerts the other police departments about the special missing person. They also contact MedicAlert ${ }^{\circledR}$, who contacts Elizabeth. The wanderer does not have to be one of the 25,000 people 
that are enrolled in the program through CaringKind. Elizabeth reaches out to the incident reporter, who is often the caregiver, to gain additional information and to provide emotional support. She explains that it is not the fault of the caregiver and that she understands the challenge of caring for someone with dementia. During her conversations with the caregiver or family, Elizabeth learns the patterns that the wanderer exhibited in the past that provide clues as to where he or she has gone. Elizabeth then posts the missing person bulletin on social media. Elizabeth noted that many wanderers forget their names and phone numbers. Sometimes female wanderers will revert to their maiden name. In anticipation of the confusion, Elizabeth collects all possible options from the family and forwards the information to hospitals and police departments.

I play the role of advocate and provide support for the caregiver.

Elizabeth gives the caregiver or family member her mobile phone number and remains an around-the-clock source of reassurance throughout the search process. Elizabeth mentioned that she reminds the caregiver or family member to take care of him or herself during the stressful time and to ask friends and family for support. The average length of time a wanderer is lost ranges from 48 to 72 hours.

I treat caregivers as though they were my family members.

MedicAlert ${ }^{\circ}$ is a national database that registers the health history and contact information of those enrolled. Healthcare and law enforcement professionals are trained to recognize the bracelets and necklaces. Elizabeth encourages all of the CaringKind clients to enroll in the MedicAlert ${ }^{\circledR}$ program. CaringKind will occasionally help with the cost of enrollment when needed (See Fig. 8.2).

The MedicAlert ${ }^{\circ}$ NYC Wanderer's Safety Program is also useful in the event of a disaster. Elizabeth shared an example of the large explosion that occurred one day in New York City. Police immediately called Elizabeth to determine whether any of the residents near the explosion had dementia so they could locate them and make sure they were safe. Elizabeth 


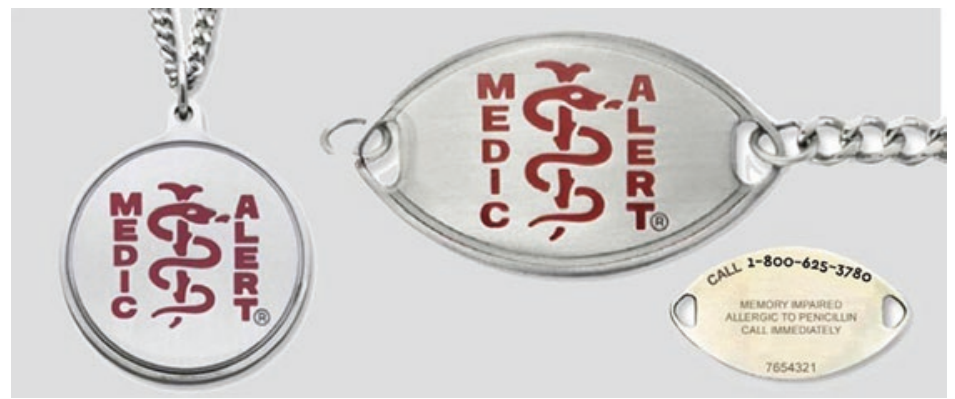

Fig. 8.2 MedicAlert ${ }^{\oplus}$ bracelet and necklace

stayed in touch with the police and the family until the people with dementia were located.

\section{Case Studies}

Caregivers of those enrolled in the program also wear a MedicAlert ${ }^{\oplus}$ bracelet or necklace with information of the person living with dementia. One day, after visiting the Veterans Administration Hospital, a husband with dementia and his wife boarded the bus home. The wife was exhausted and fell asleep during the bus ride. When she awoke, her husband was gone. The wife was in a panic when she approached the bus driver to ask whether he had seen her husband leave the bus. Her English was broken at best. She gave her necklace to the driver who then knew to call the police and report the man missing. The husband was found at a local hospital before the day ended.

MedicAlert ${ }^{\oplus}$ is an international program, which was useful to Elizabeth when a person with dementia from New York City walked into a beauty parlor in Jamaica. He told the owner he was waiting for his wife, but when it was time to close the shop, the owner became concerned. She noticed his bracelet and contacted MedicAlert ${ }^{\circledast}$ who then contacted Elizabeth. The family had notified Elizabeth that they would be in Jamaica on vacation so she was prepared. Elizabeth called the family and they retrieved their dad. 
I wish people would understand that low-tech solutions can have great impact. The person reading the MedicAlert ${ }^{\circledR}$ bracelet or necklace does not need anything more than the ability to read. Our system is simple, but it works.

\section{Program Staffing}

The CaringKind Wanderer's Safety Program has only two employees other than Elizabeth. This program is inexpensive for CaringKind to operate, but it has meaningful impact.

Dementia-friendly clinical settings can also have meaningful impact. When the care systems and clinical settings are designed with the cognitive challenges of someone living with dementia in mind, they can help mitigate adverse physical and emotional events.

Every time you change the place or the people who are interacting with the person with dementia, disorientation and fear increases. We need standardized models of care that address changing caregivers and locations for dementia patients. (Davina Porock)

\section{Davina Porock, PhD}

At the time of her interview, Davina Porock was the Vice Provost for Faculty and Administration at Lehman College, City University of New York. She has practiced nursing and conducted dementia research nationally and internationally.

In her interview Davina highlighted the importance of not moving people with dementia around as much as other patients in the hospital setting. Those with dementia become easily disoriented and frightened when moved into a loud emergency department and then into a new room on another floor, and then around for different tests and procedures. Davina suggested providers should adjust their systems to enable patients with dementia to be in one quiet place as much as possible. 
Davina also described how the built environment within a clinical setting can support patients with dementia. People with dementia have visual spatial challenges. Davina gave an example from a long-term care facility in the United Kingdom where she had previously worked. The bathrooms were all white. Patients were unable to find exactly where the toilet was and often ended up sitting in the wrong place, resulting in discomfort or a fall. When they changed the toilet seat to black, this issue was resolved.

Patients with dementia often like to walk around. The management of a long-term care facility that Davina worked for installed pictures at the end of each hallway that changed electronically to keep people occupied and to make the walk more interesting. The management also simplified the signage and made it yellow and black, which is the last color differences that can be seen by someone with dementia. The signs were hung at eye height so people did not have to look up for them.

These methods resulted in lowering the length of stay for people with dementia. Normally a person with dementia, who presents with the same illness or injury of a person without dementia, will stay longer in a care facility. With the dementia-friendly interventions, Davina and her team were able to make those stay times equal.

Dementia-friendly clinical settings are growing in importance as the rates of dementia continue to multiply. They are steps toward building a society that is welcoming and inclusive for those living with dementia. The Dementia Action Alliance ${ }^{45}$ is dedicated to building a dementiainclusive America.

We are trying to respectfully disrupt the beliefs, attitudes, and practices about dementia in our country. (Karen Love)

\section{Karen Love, Jackie Pinkowitz, and Lon Pinkowitz, The Dementia Action Alliance}

Karen Love is the Founder and Executive Director, Jackie Pinkowitz is the Chair of the Board, and Lon Pinkowitz serves on the Board of Directors of the Dementia Action Alliance (DAA).

The Dementia Action Alliance envisions a society where dementia symptoms are better understood and accommodated as a disability, and 
individuals and families living with dementia are fully included and supported.

The DAA is a diverse coalition of passionate people, organizations, companies, and communities that are "committed to creating a better society now for individuals to live with dementia." The Alliance enables numerous learning exchanges among diverse stakeholders, including those living with dementia, through:

- The Advisory Council of persons living with dementia symptoms provides guidance from the perspective of their lived experience. Their insight and input are crucial to the vision, mission, and goals of the Dementia Action Alliances.

- The Scientific Advisory Board is comprised of professionals with diverse knowledge and expertise about person-centered dementia care and services across research, policy, and practice. The board provides technical, clinical, and scientific guidance for advancing Dementia Action Alliance initiatives.

- Workgroups: Optimizing Wellbeing, Technology, and Arts and Dementia.

- An online resources center.

- Community presentations and conversations.

We want healthcare clinicians to understand that people living with dementia are people first and patients second. (Jackie Pinkowitz)

\section{Stigma}

In their 2016 white paper, Walk with Me, ${ }^{46}$ the Canadian Research Institute for Aging ${ }^{47}$ identified three barriers that prevent older adults from living life fully. Those barriers include ageism and stigma, segregation from community, and the pervasive medicalized and deficitfocused views on aging. People with dementia often feel a sense of shame and reduced status within society. ${ }^{48}$ Many seek to hide their diagnosis. ${ }^{49}$ Some resort to isolating themselves from their community. Caregivers and families feel the stigma by association, adding 
stress to an already overwhelming care burden. ${ }^{50}$ Stigmas focus on limitations rather than strengths. This is juxtaposed to how people with dementia wish to be viewed. ${ }^{51}$ The Dementia Action Alliance hopes to reduce the stigma of dementia through connection and conversation.

It is all too easy to see someone's challenges before we see the person. (Karen Love)

Caring Conversations are friendly, informal gatherings aimed at changing the perceptions of people living with dementia. The DAA hosts conversations in communities throughout the US. The conversations always include people living with dementia and are open to the community including healthcare professionals, local law enforcement, business owners, and caregivers. Karen, Jackie, and Lon view the conversations as small community dementia-related think tanks. The community members can interact with people who are living with dementia and learn about them as people, which help participants see the person before their disease. Karen mentioned that it is their hope that when participants leave the conversation, they will say, "There is the artist," rather than, "There is the woman with dementia." Jackie hopes that these conversations will build community champions who will carry the conversations further and promote dementia inclusion in their community.

The DAA strives to dispel the myth that those living with dementia are not vital contributors to their communities and to society as a whole. In their interview, Karen, Jackie, and Lon expressed the importance of involving the stakeholders in all areas of policy that affect those living with dementia. In this case, stakeholders might include caregivers, families, and more obviously people living with dementia. Karen expressed her disappointment that the US government built a federal advisory council for dementia that included researchers and clinicians, but no people living with dementia. Jackie used the phrase "Nothing about us without us," which was the title of an influential book about disability. ${ }^{52}$ Karen, Jackie, and Lon believe that communities and businesses should adapt to include people living with 
dementia as they have for those living with disability. Some from the Dementia Action Alliance Advisory Board have brought their perspectives to local, state, and federal policy makers and remain active in the world of dementia policy. One of those advisors is Brian LeBlanc.

Hopefully we can inspire honest conversations and slowly chip away at the pervasive stigma and fear that surround dementia. (Brian LeBlanc)

\section{Brian Leblanc, Dementia Action Alliance}

Brian LeBlanc is a public speaker and dementia advocate. He is the fourth generation in his family to have Alzheimer's disease. He is on the advisory board of the Dementia Action Alliance and the leadership board of Covenant Care. He is also on the National Early Stage advisory group of the Alzheimer's Association.

Brian speaks publicly and advocates tirelessly so people can understand that those living with Alzheimer's disease are "people like everyone else" who offer value to society. He shares his personal history and journey with the disease because too many hide their diagnosis for fear of being treated differently. He mentioned in his interview that he does not try to "paint a rosy picture" of Alzheimer's disease because it is difficult, but he wants the public to see him as a man who likes to go to concerts and Disneyland before they see his struggles.

Brian is a musician and he loves to sing. He described how the faces of the residents in memory care light up when he performs for them. He had some friends ask him whether it made him uncomfortable to see people in the later stages of dementia. He responded, "I hope someone like me will come and sing songs to me when I am in their position."

Brian mentioned that he has good days and bad days. Recently he lost his ability to speak. This was a stressful period for him and his family. After a couple of weeks, and during an anniversary trip with his wife Shannon to Disneyland, Brian's ability to speak returned. When he described this he said, "Disney Land is the happiest place on earth." In one of his blogs, Brian wrote that he has not stopped talking since and 
when his family is away he talks to his dog Dallas, who is a great listener and never disagrees. In his blog, Alzheimer's: The Journey, Brian shares his experience of living with Alzheimer's. ${ }^{53} \mathrm{He}$ can also be found advocating on Facebook, LinkedIn, and Twitter. The tagline of his blog reads, $I$ have Alzheimer's BUT, it doesn't have me! We believe him.

Our next chapter describes the way forward to sustainably care for the global aging population by merging health and social supports to address the biopsychosocial and environmental needs of older adults. This upstream facing idea aims to meet needs that, if unmet, result in physical and mental illness and injury. It carries with it more than an ounce of prevention and improves patient engagement resulting in in greatly reduced healthcare utilization and spending.

The full interviews referenced in this chapter can be found at this link: www.accessh.org/agingwell.

\section{Notes}

1. Alzheimer's Disease International (2015). World Alzheimer report 2015: The global impact of dementia. https://www.alz.co.uk/research/ WorldAlzheimerReport2015.pdf. Accessed April 2017.

2. Ibid.

3. Ibid.

4. Ibid.

5. Friedman, E.M., Regina, S.A., Langa, K.M., \& Hurd, M.D. (2015). US prevalence and predictors of informal caregiving for dementia. Health Affairs, 34(10), 1637-1641.

6. Alzheimer's Association, (2017). 2017 Alzheimer's disease facts and figures. http://www.alz.org/facts/. Accessed April 2017.

7. Hurd, M.D., Martorell, P, Delavande, A., Mullen, K., \& Langa, K.M. (2013). Monetary costs of dementia in the US. New England Journal of Medicine, 368(14), 1326-1334.

8. World Health Organization, (2016). Dementia. Fact Sheet. http://www. who.int/mediacentre/factsheets/fs362/en/. Accessed April 2017.

9. World Health Organization, (2012). Dementia. A public health priority. http://apps.who.int/iris/bitstream/10665/75263/1/9789241564458_ eng.pdf?ua=1. Accessed April 2017. 
10. Alzheimer's Disease International. (2013). World Alzheimer Report 2013 reveals global Alzheimer's epidemic creating shortage of caregivers, lack of support from family members. https://www.alz.co.uk/ media/130919. Accessed April 2019.

11. Graham, J. (2014). A shortage of caregivers. The New York Times. https:// newoldage.blogs.nytimes.com/2014/02/26/a-shortage-of-caregivers/?_ $\mathrm{r}=0$. Accessed April 2017.

12. World Health Organization. Supporting in formal caregivers of people living with dementia. http://www.who.int/mental_health/neurology/ dementia/dementia_thematicbrief_informal_care.pdf?ua=1. Accessed April 2017.

13. World Health Organization. Supporting in formal caregivers of people living with dementia. http://www.who.int/mental_health/neurology/ dementia/dementia_thematicbrief_informal_care.pdf?ua=1. Accessed April 2017.

14. Feinberg, L. \& Rita Choula. Understanding the impact of family caregiving on work. AARP Public Policy Institute. http://www.aarp.org/content/dam/aarp/research/public_policy_institute/ltc/2012/ understanding-impact-family-caregiving-work-AARP-ppi-ltc.pdf. Accessed April 2017.

15. Michalowsky, B., Thyrian, J.R., Eichler, T., Hertel, J., Wucherer, D., Flessa, S., \& Hoffman, W. (2016). Economic analysis of formal care, informal care, and productivity losses in primary care patients the screen positive for dementia in Germany. Journal of Alzheimer's Disease, 50(1), 47-59.

16. Alzheimer's Association, (2017). 2017 Alzheimer's disease facts and figures. http://www.alz.org/facts/. Accessed April 2017.

17. Michalowsky, B., Thyrian, J.R., Eichler, T., Hertel, J., Wucherer, D., Flessa, S., \& Hoffman, W. (2016). Economic analysis of formal care, informal care, and productivity losses in primary care patients the screen positive for dementia in Germany, 50(1), 47-59.

18. Reinhard, S.C., Given, B., Petlick, N.H., \& Bernis, A. (2008). Supporting family caregivers and providing care. In: Hughes, R.G. Editor. Patient safety and quality: An evidence-based handbook for nurses. Rockville (MD): Healthcare Research and Quality (US). Chapter 14. https://www.ncbi.nlm.nih.gov/books/NBK2665/. Accessed April 2017.

19. Zwaanswijk, M., Peeters, J.M., van Beek, A., Meerveld, J., \& Francke, A. (2013). Informal caregivers of people with dementia: problems, needs 
and support in the initial stage and in subsequent stages of dementia: a questionnaire survey. Open Nursing Journal. 7, 6-13.

20. Ibid.

21. Alzheimer's Association, (2017). 2017 Alzheimer's disease facts and figures. http://www.alz.org/facts/. Accessed April 2017.

22. (2010). How much is dementia care worth? Lancet Neurology, 9(11), 1037.

23. Vandepitte, S., Van Den Noortgate, N., Putman, K., Verhaeghe. S., Faes, K., \& Annemans, L. (2016). Effectiveness of supporting informal caregivers of people with dementia: A systematic review of randomized and non-randomized controlled trials. Journal of Alzheimer's Disease, 52(3), 929-65.

24. Mittelman. M.S., Roth, D.L., Clay, O.J. \& Haley, W.E. (2007). Preserving health of Alzheimer caregivers: Impact of a spouse caregiver intervention. 15(9):78-798.

25. Mittelman, M.S., Roth, D.L., Coon, D.W., \& Haley, W.E. (2004). Sustained benefit of supportive intervention for depressive symptoms in Alzheimer's caregivers. American Journal of Psychiatry, 161(5), 850-856.

26. Mittelman, M.S., Roth, D.L., Haley, W.E., \& Zarit, S.H. (2004). Effects of a caregiver intervention on negative caregiver appraisals of behavior problems in patients with Alzheimer's disease: Results of a randomized trial. Journal Gerontology, Psychological Sciences, 59(1), 27-34.

27. Mittelman, M.S., Haley, W.E., Clay, O.J., \& Roth, D.L. (2006). Improving caregiver wellbeing delays nursing home placement of patients with Alzheimer's disease. Neurology, 67(9), 1592-1599.

28. Mittelman, M.A., Roth, D.L., Clay, O.J. \& Haley, W.E. (2007). Preserving health of Alzheimer's caregivers: Impact of a spouse caregiver intervention. American Journal of Geriatric Psychiatry, 15(9), 180-189.

29. Mittelman, M.A., \& Bartels, S.J. (2014). Translating research and practice: Case study of the community-based metric caregiver intervention. Health Affairs, 33(4), 587-595.

30. Luchinsinger, J.A., Burgio, L., Mittelman, J., Dunner, I., Levine, J.A., King, J., Silver, S., Ramirez, M, \& Teresi, J.A. (2016). Northern Manhattan Hispanic caregiver intervention effectiveness study: Protocol of a programmatic randomized trial comparing the effectiveness of two established interventions for informal caregivers of persons with dementia. BMJ Open, 6(11), e014082. 
31. Gaugler, J.E., Reese, M., \& Mittelman, M. (2015). Effects of the Minnesota adaptation of the NYU caregiver intervention on primary subjects stress of adult child caregivers of persons with dementia. Gerontologist, 56(3), 461-471.

32. Gaugler, J.E., Reese, M., \& Mittelman, M. (2015). Effects of the Minnesota adaptation of the NYU caregiver intervention and depressive symptoms and quality of life for adult child care givers of persons with dementia. American Journal of Geriatric Psychiatry, 23(11), 1179-1192.

33. Foldes, S.S., \& Long K.H. (2014). http://www.actonalz.org/sites/ default/files/documents/MN\%20Economic\%20Model\%20of\%20 Dementia\%20White\%20Paper\%20Final.pdf. Accessed April 2017.

34. https://www.amazon.com/Counseling-Alzheimers-Caregiver-ResourceProfessionals/dp/1579472621.

35. Robins, L. (2015). With an influx of newcomers, little Chinatowns dot a changing Brooklyn. New York Times. https://www.nytimes. com/2015/04/16/nyregion/influx-of-chinese-immigrants-is-reshapinglarge-parts-of-brooklyn.html?_r=0. Accessed May 2017.

36. Alzheimer's Association. African-Americans and Alzheimer's Disease: The silent epidemic. https:/www.alz.org/national/documents/report_ africanamericanssilentepidemic.pdf. Accessed May 2017.

37. Alzheimer's Association. African-Americans are at a higher risk for Alzheimer's disease. Accessed May 2017.

38. Kleinfield, N.R. (2016). Fraying at the edges. New York Times. https:// www.nytimes.com/interactive/2016/05/01/nyregion/living-withalzheimers.html?_r=0. Accessed April 2017.

39. Warshaw, G.A., \& Bragg, E. (2014). Preparing the health care workforce to care for adults with Alzheimer's disease and related dementias. Health Affairs, 33(4), 633-41.

40. Henriques, C. (2016). https://alzheimersnewstoday.com/2016/03/31/ caregivers-of-people-with-dementia-face-financial-hardships/. Accesses May, 2017.

41. https://www.caringkindnyc.org/_pdf/CaringKind-PalliativeCare Guidelines.pdf. Accessed May 2017.

42. Alzheimer's Association. Wandering and getting lost. http://www.alz. org/norcal/in_my_community_18411.asp. Accessed May 2017.

43. Weeks, L. (2009). Understanding dementia and 'wandering'. The mysteries of dementia-driven wandering. National Public Radio.

44. http://www.caringkindnyc.org/wandersafety/. Accessed May 2017. 
45. http://daanow.org. Accessed May 2017.

46. http://www.the-ria.ca/walkwithme/livingfully/. Accessed June 2017.

47. Canadian Research Institute for Aging. Accessed June 2017.

48. Batsch, N.L., \& Mittelman, M.S. (2012). Overcoming the stigma of dementia. World Alzheimer's Report 2012. Alzheimer's Disease International. Pg. 9.

49. Alzheimer's Association (2008). Voices of Alzheimer's disease: A summary report on the nationwide town hall meeting for people with early stage dementia. https://www.alz.org/national/documents/report_townhall.pdf. Accessed May 2017.

50. Batsch, N.L., \& Mittelman, M.S. (2012). Overcoming the stigma of dementia. World Alzheimer's Report 2012. Alzheimer's Disease International. Pg. 11.

51. Alzheimer's Association (2008). Voices of Alzheimer's disease: A summary report on the nationwide town hall meeting for people with early stage dementia. https:/www.alz.org/national/documents/report_townhall.pdf. Accessed May 2017.

52. Nothing About Us Without Us. Disability Oppression and Empowerment. By James I. Carlton.

53. https://abitofbriansbrilliance.com. Accessed May 2017.

Open Access This chapter is licensed under the terms of the Creative Commons Attribution 4.0 International License (http://creativecommons.org/licenses/ by/4.0/), which permits use, sharing, adaptation, distribution and reproduction in any medium or format, as long as you give appropriate credit to the original author(s) and the source, provide a link to the Creative Commons licence and indicate if changes were made.

The images or other third party material in this chapter are included in the chapter's Creative Commons licence, unless indicated otherwise in a credit line to the material. If material is not included in the chapter's Creative Commons licence and your intended use is not permitted by statutory regulation or exceeds the permitted use, you will need to obtain permission directly from the copyright holder.

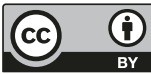

